\title{
Short communication: Herd-level reproductive performance and its relationship with lameness and leg injuries in freestall dairy herds in the northeastern United States
}

\author{
N. Chapinal, ${ }^{*}$ M. A. G. von Keyserlingk, ${ }^{*}$ R. L. A. Cerri,† K. Ito, ${ }^{*} \ddagger$ S. J. LeBlanc, $\S$ and D. M. Weary* ${ }^{* 1}$ \\ *Animal Welfare Program, University of British Columbia, Vancouver, BC V6T 1Z4, Canada \\ †Faculty of Land and Food Systems, University of British Columbia, Vancouver, BC V6T 1Z4, Canada \\ ¥Novus International Inc., St. Charles, MO 63304 \\ §Population Medicine, University of Guelph, Guelph, ON N1G 2W1, Canada
}

\section{ABSTRACT}

The objectives of this study were to describe herdlevel reproductive outcomes and their associations with the prevalence of lameness, hock injuries and knee injuries in freestall dairy herds in the northeastern United States. Five reproductive outcomes (calving to conception interval, CCI; calving interval, CI; conception risk at the first artificial insemination, CR1; insemination rate, IR; and pregnancy rate, $\mathrm{PR}$ ) were measured from Dairy Comp 305 (Valley Agricultural Software, Tulare, CA) for a 12-mo period for all multiparous cows in each of the 53 herds assessed. The prevalence of lameness, hock injuries, and knee injuries was assessed in 1 highproducing group. The means ( \pm standard deviation) for the 5 reproductive outcomes were as follows: CCI $=$ $128 \pm 10 \mathrm{~d}, \mathrm{CI}=404 \pm 10 \mathrm{~d}, \mathrm{CR} 1=36 \pm 5 \%, \mathrm{IR}=$ $60 \pm 7 \%$, and $\mathrm{PR}=20 \pm 3 \%$. The average prevalence of clinical lameness, hock injuries, and knee injuries were $45 \pm 20 \%, 58 \pm 31 \%$, and $16 \pm 15 \%$, respectively. Univariable associations between the reproductive outcomes and the prevalence of lameness and leg injuries were tested and significant predictors were submitted to a model that controlled for the confounding effects of herd size, 305-d mature equivalent milk production of the high-producing group, and use of deep bedding. A higher prevalence of lameness was associated with poorer reproductive performance, although the relationships were weak: herds with a higher prevalence of lameness had longer average CCI (slope estimate $=$ $0.16 \pm 0.07 ; \mathrm{R}^{2}=0.09$ ) and CI (slope estimate $=0.14$ $\left.\pm 0.07 ; R^{2}=0.07\right)$. These results indicate that management to reduce lameness may improve reproductive performance.

Key words: cow comfort, fertility, gait, skin lesion

Received April 26, 2013.

Accepted August 5, 2013

${ }^{1}$ Corresponding author: dan.weary@ubc.ca

\section{Short Communication}

Infertility and lameness are two of the most serious problems in modern dairy herds. The prevalence of lameness has increased worldwide (Espejo et al., 2006; Dippel et al., 2009; von Keyserlingk et al., 2012) while reproductive performance has gradually declined (Washburn et al., 2002; VanRaden et al., 2004; Norman et al., 2009). Some of the economic losses associated with lameness are thought to be due to effects on fertility (Garbarino et al., 2004; Bicalho et al., 2007). The relationship between lameness and reproduction has been studied at the cow level. Lameness after calving has been associated with delayed cyclicity (Garbarino et al., 2004), higher incidence of ovarian cysts and lower pregnancy to first AI (Melendez et al., 2003), and longer intervals from calving to first AI and to conception (calving to conception interval, CCI) (Sprecher et al., 1997; Hernandez et al., 2005; Bicalho et al., 2007). Pain associated with lameness alters behavior, weakening the expression of estrus (Walker et al., 2010) and reducing feed intake (González et al., 2008), both of which may lower reproductive performance. Hock and knee injuries are also common in modern dairy herds (Kielland et al., 2009; Lombard et al., 2010; von Keyserlingk et al., 2012). These injuries may also alter cows' behavior and affect reproduction in a similar way to lameness; however, to our knowledge, no previous research has examined these linkages.

The effect of lameness and leg injuries on reproduction may vary from cow to cow, but these problems are typically managed at the herd level. Reproductive performance is also typically assessed with herd-level measures such as conception risk (CR), insemination rate (IR; formerly known as heat detection rate), and pregnancy rate $(\mathbf{P R})$. Insemination rate and PR include all the cows in the herd that are eligible to be bred, as opposed to measures such as average CCI or calving interval (CI), which exclude cows that fail to become pregnant. Pregnancy rate is determined by $\mathrm{CR}$ and IR (with many variables in turn influencing 
each of these measures); thus, PR is likely the most comprehensive single measure to assess herd reproductive performance. To the best of our knowledge, the relationship between herd-level reproductive outcomes and the prevalence of lameness, hock injuries, and knee injuries has not been studied.

The objective of this study was to investigate the associations between herd-level reproductive outcomes and the prevalence of lameness, hock injuries, and knee injuries in freestall dairy herds in the northeastern United States, a region known to suffer high rates of lameness and leg injuries (von Keyserlingk et al., 2012). In this study, we focused on multiparous cows, because this group of animals is most likely to experience lameness (Offer et al., 2000; Chapinal et al., 2010), leg injuries (Rutherford et al., 2008; Kielland et al., 2009), and infertility (Chebel et al., 2004; Santos et al., 2009). A second objective was to describe the reproductive performance of freestall dairy herds in this region.

A total of 53 herds in the northeastern United States (Connecticut $\mathrm{n}=1$; New York $\mathrm{n}=48$; Pennsylvania $\mathrm{n}=1$; Vermont $\mathrm{n}=3$ ) were selected from within the Novus C.O.W.S. program, a partnership between The University of British Columbia and Novus International Inc. (http://www.novusint.com/en/Market-Segments/ Dairy/COWS), for this observational study. All herds meeting the following inclusion criteria were included in the study: Holstein cows, freestall housing, feeding a TMR, and use of the herd management software Dairy Comp 305 (Valley Ag Software, Tulare, CA). The mean $( \pm \mathrm{SD})$ herd size was $863 \pm 488$ milking cows and the mean 305-d mature-equivalent milk production was $12,278 \pm 873 \mathrm{~kg}$. All methods used to collect data were approved by the University of British Columbia's Animal Care Committee, which follows the standards outlined by the CCAC (2009).

Herds were visited between July 2010 and July 2012. In each herd, the manager selected a "high-producing" pen of primarily multiparous cows (mean \pm SD group size $=172 \pm 77$ cows; lactation number $=2.9 \pm 0.4$; $\mathrm{DIM}=148 \pm 46 \mathrm{~d}$; 305-d mature-equivalent milk production $=12,177 \pm 950 \mathrm{~kg}$ ) for assessing lameness and leg injuries. The first 25 of the 53 herds assessed were also included in von Keyserlingk et al. (2012), Barrientos et al. (2013), and Chapinal et al. (2013), but none of those papers reported reproductive outcomes.

All cows housed in the high-producing pen were gait scored as they exited the parlor using a 5-point Numerical Rating System (NRS), where $1=$ sound and $5=$ severely lame (Flower and Weary, 2006; Chapinal et al., 2009). Cows with NRS $\geq 3$ were considered clinically lame, and cows with NRS $\geq 4$ were considered severely lame. A total of 9,103 cows were scored. The percent- age of clinically and severely lame cows was calculated for each herd.

A sample of 38 to 40 primarily multiparous focal cows (mean $\pm \mathrm{SD}$ lactation number $=2.8 \pm 0.4$; DIM $=140 \pm 38)$ were selected from the high-producing pen (as described in von Keyserlingk et al., 2012) to be assessed for hock injuries. Hock (lateral surface of the tarsal joint) injuries were assessed during milking on a 3 -point scale, where $1=$ healthy hock and $3=$ swollen hock, open wound, or both, according to the Hock Assessment Chart for Cattle developed by Cornell Cooperative Extension (http://www.ansci.cornell. edu/prodairy/pdf/hockscore.pdf). Only one hock per cow was considered for this assessment because of the difficulty in examining the opposite side in herringbone parlors. A total of 2,091 cows were scored. The percentage of cows with clinical hock injury (score $\geq 2$ ) and with severe hock injury ( score $=3$ ) were calculated.

Knee (carpal joint) injuries were recorded as present (evidently swollen joint with or without skin damage) or absent on each knee (as described in von Keyserlingk et al., 2012). All cows in the high-producing group were examined in 27 of the herds and only the focal cows were examined in the other 26 herds. A total of 5,739 cows were scored. The percentage of cows with at least one knee injury was calculated.

A total of 3 trained observers performed the lameness and leg injury assessments, but within any one herd the same observer scored all cows for lameness and injuries. Prevalence-adjusted bias-adjusted kappa (Byrt et al., 1993; Thomsen and Baadsgaard, 2006) was calculated to assess inter-observer agreement for each lameness and leg injury score; this kappa estimate ranged from 0.83 to $0.93(P<0.001)$, indicating near-perfect agreement (Landis and Koch, 1977).

Reproductive outcomes were retrieved from Dairy Comp 305 (Valley Ag Software), considering the total number of multiparous cows (lactation $\geq 2$ ) present in the herd at the time of the visit and the multiparous cows culled or sold in the 14 mo before the herd visit. On average $( \pm \mathrm{SD}), 1,045 \pm 792$ multiparous cows per herd were included in the analysis $(\mathrm{n}=55,361 \mathrm{mul}-$ tiparous cows in total). The following cow-level reproductive outcomes were retrieved: calving to first AI interval (considering all multiparous cows except for fresh cows that had not yet been bred), CCI (considering multiparous cows with confirmed pregnancy), and CI between the last 2 calving events. The distribution of the calving to first AI intervals was used to estimate the voluntary waiting period (VWP), defined as the interval postpartum by which $10 \%$ of the multiparous cows with a first AI had received their first AI (Miller et al., 2007). Four herd-level reproductive 
outcomes were also retrieved, considering multiparous cows and the time period from 14 to 2 mo before the visit: CR at the first AI (CR1; defined as the number of known pregnant animals divided by the number of inseminated animals with known outcomes, considering only the first AI after calving, and multiplied by 100), 21-d IR (number of animals inseminated divided by the number of cows eligible to be inseminated in a given 21-d interval, multiplied by 100), 21-d PR (number of known pregnant animals divided by the number of cows eligible to become pregnant in a given 21-d interval, multiplied by 100), and the percentage of AI that were based on synchronization and timed AI. This 12-mo period was selected to avoid bias due to seasonal fluctuations, and to have known pregnancy outcomes for the cows considered in the calculations (i.e., cows bred in the 2 mo before the visit might not have had known pregnancy outcomes recorded in Dairy Comp 305 at the time of the visit). For the calculation of PR and IR, cows were considered eligible to be inseminated or pregnant when DIM $\geq$ VWP (calculated as described above or standardized to $50 \mathrm{~d}$, the default VWP in Dairy Comp 305), the cow was not already pregnant, and was not recorded as "do not breed" [on average $( \pm \mathrm{SD}), 3.2 \pm 2.7 \%$ of the multiparous cows present on each farm during the study period were recorded as "do not breed"]. Insemination rate and PR were calculated in 21-d intervals by Dairy Comp 305, and one summary value for each outcome was then calculated for the study period (14 to 2 mo before the visit).

Data handling and statistical analyses were performed with SAS (version 9.2, SAS Institute Inc., Cary, NC). Descriptive statistics were calculated with PROC UNIVARIATE. Reproductive outcomes measured at the cow level (calving to first AI interval, CCI, and CI) were screened for outliers by visual assessment of the distributions. Extreme outliers (observations more than 3 times the interquartile range from the first or third quartile of the data set) or values that were not biologically plausible (i.e., calving to first $\mathrm{AI}$ interval or CCI $<21$ d or CI $<300$ d) were discarded. The number of observations discarded amounted to $0.9 \%$ for calving to first AI interval, $0.4 \%$ for CCI, and $0.9 \%$ for CI. Data were then averaged across cows to obtain one value per herd.

Herd was the experimental unit for all statistical analyses. Of the reproductive measures recorded, 5 were selected to test the effect of the prevalence of lameness and leg injuries on reproductive performance: CCI, CI, CR1, PR, and IR. These measures have been considered representative of aspects of herd reproductive performance (e.g., DeVries and Risco, 2005; Norman et al., 2009; Morton, 2010), although CCI and CI are biased by exclusion of cows that fail to become pregnant. Uni- variable analyses were performed to assess the association between reproductive outcomes and the prevalence of lameness and leg injuries (PROC REG). Linearity between outcome variables and continuous predictors was assessed graphically and by testing the quadratic term in the model. Predictors with a univariable association of $P \leq 0.10$ were submitted to a multivariable model (PROC REG), controlling for the effect of 3 potential confounders: herd size, 305-d mature-equivalent milk production of the high-producing assessment group, and use of deep bedding. Correlations among explanatory variables were calculated to avoid submitting highly correlated variables $(|\mathrm{r}|>0.70)$ to the same model. Explanatory variables were removed from the final model if $P>0.05$ through manual backward elimination. Residuals were examined after each model to verify normality and homogeneity of variance. Outliers, high leverage points, and observations with an undue influence in the model were examined using residuals, leverage values, and Cook's distances.

The prevalence of lameness and leg injuries and the reproductive outcomes are described in Table 1 . At the univariable level (Figure 1), the prevalence of clinical lameness was associated with the herd-average CCI (slope estimate $=0.16 \pm 0.07 ; \mathrm{R}^{2}=0.09 ; P=0.03$ ) and CI (slope estimate $=0.14 \pm 0.07 ; \mathrm{R}^{2}=0.07 ; P=0.05$ ). The prevalence of severe lameness was also associated with herd-average CCI (slope estimate $=0.34 \pm 0.16$; $\mathrm{R}^{2}=0.08 ; P=0.04$. However, the prevalence of clinical and severe lameness were highly correlated $(\mathrm{r}=0.72$; $P<0.001)$ and these were not submitted to the same multivariable model. No association was found between the prevalence of cows with hock and knee injuries and any of the reproductive outcomes $(P>0.10)$. Predictors significant at the univariable level were submitted to a model that included herd size, 305-d mature-equivalent milk production of the high-producing group, and use of deep bedding. However, none of those covariates remained in the model $(P>0.10)$ and consequently, all final models contained one single predictor.

As reported by von Keyserlingk et al. (2012), lameness, hock, and leg injuries were common in dairy herds in the northeastern United States, yet the prevalence varied across herds. Although all herds had some clinical lameness and hock injuries, severe lameness, severe hock injuries, and knee injuries were not present in all herds. Other research in North America and Europe (e.g., Espejo et al., 2006; Dippel et al., 2009; Kielland et al., 2009) has also shown that lameness and leg injuries are common. The variability in these ailments across herds suggests that prevention is possible through changes in management and housing.

The broad range in the percentage of timed AI, the VWP, and the herd-average calving to first AI interval 
Table 1. Prevalence of lameness and leg injuries and herd reproductive outcomes for multiparous cows in 53 dairy herds in the northeastern United States

\begin{tabular}{|c|c|c|c|}
\hline Variable & Mean & SD & Range \\
\hline \multicolumn{4}{|l|}{ Lameness and leg injuries $^{1}$} \\
\hline Clinical lameness (\%) & 45 & 20 & $14-88$ \\
\hline Severe lameness $(\%)$ & 8 & 9 & $0-45$ \\
\hline Clinical hock injuries (\%) & 58 & 31 & $5-100$ \\
\hline Severe hock injuries (\%) & 4 & 5 & $0-30$ \\
\hline Knee injuries (\%) & 16 & 15 & $0-53$ \\
\hline \multicolumn{4}{|l|}{ Reproduction } \\
\hline Timed AI ( $\%$ of all inseminations) & 51 & 18 & $6-90$ \\
\hline Voluntary waiting period ${ }^{2}$ (VWP; d) & 61 & 7 & $49-77$ \\
\hline Calving to first AI interval (d) & 71 & 5 & $61-85$ \\
\hline Calving to conception interval ${ }^{3}$ (d) & 128 & 10 & $102-147$ \\
\hline Calving interval $^{3}(\mathrm{~d})$ & 404 & 10 & $385-427$ \\
\hline Conception risk at the first $\mathrm{AI}^{3}(\%)$ & 36 & 5 & $25-50$ \\
\hline 21 -d Insemination rate $^{3,4}(\%)$ & 60 & 7 & $46-73$ \\
\hline 21-d Insemination rate standardized at VWP $=50 \mathrm{~d}(\%)$ & 56 & 6 & $39-70$ \\
\hline 21-d Pregnancy rate re $\left.^{3,4} \%\right)$ & 20 & 3 & $14-29$ \\
\hline 21-d Pregnancy rate standardized at VWP $=50 \mathrm{~d}(\%)$ & 19 & 3 & $13-29$ \\
\hline
\end{tabular}

${ }^{1}$ Assessed once in 1 high-producing group.

${ }^{2}$ Defined as the interval postpartum by which $10 \%$ of the multiparous cows with a first AI had received their first AI.

${ }^{3}$ Reproductive outcomes selected to evaluate the effect of lameness and leg injuries prevalence on reproductive performance.

${ }^{4}$ Calculated using the VWP estimated for each herd.

suggests great variability in reproductive management across herds. All the herds enrolled in this study combined estrus detection with timed AI, although the percentage of timed AI varied from 6 to $90 \%$ of the total AI. Similarly, Caraviello et al. (2006) surveyed herds in different regions of the United States and found that $87 \%$ of the herds used some timed AI, with diverse synchronized breeding protocols. Other studies have reported lower use of timed AI in the United States (Olynk and Wolf, 2008; Miller et al., 2007; 45 and $20 \%$ of the herds, respectively). The higher proportion of herds using synchronized breeding programs in our study could be explained by increasing use of such programs in the last decade (Miller et al., 2007) as well as differences in the inclusion criteria when selecting herds (e.g., herds using Dairy Comp 305 may be more likely to use timed AI).

As in other studies (Miller et al., 2007; DeVries et al., 2010), we calculated the VWP assuming that it was constant across multiparous cows, although the VWP can be affected by factors such as milk production, BCS, or season (Caraviello et al., 2006; DeJarnette et al., 2007). We estimated an average VWP of $61.5 \mathrm{~d}$, similar to the VWP of $60 \mathrm{~d}$ assumed for national genetic evaluations for daughter PR in the United States (VanRaden et al., 2004) and higher than the default VWP of $50 \mathrm{~d}$ used by Dairy Comp 305. Other studies conducted in the United States reported an average VWP ranging from 52 to $56 \mathrm{~d}$, as estimated through surveys (Caraviello et al., 2006; DeJarnette et al., 2007) or calculated from the distribution of calving to first AI intervals (Miller et al., 2007; DeVries et al., 2010). That all herds in the current study used timed AI may have contributed to the slightly longer VWP, as longer VWP are recommended with synchronized breeding programs (Tenhagen et al., 2003). Voluntary waiting periods have also shown a gradual increase over the past decade (DeVries et al., 2010). The use of timed AI in the study herds also likely contributed to the lower average calving to first $\mathrm{AI}$ interval of $71 \mathrm{~d}$, compared with the range of 85 to $100 \mathrm{~d}$ reported for Holstein cows in the United States (Washburn et al., 2002; Norman et al., 2009; DeVries et al., 2010). Miller et al. (2007) also cited increased use of timed AI as a factor explaining reduction in the calving to first $\mathrm{AI}$ interval.

The current study used cow-level variables averaged across cows within herd (CCI, CI) and herd-level variables (CR1, IR, PR) to describe reproductive performance. We report average CCI and CI because they are widely used to describe herd reproductive performance (Washburn et al., 2002; Löf et al., 2007; Norman et al., 2009), but we also encourage caution in their interpretation. Their distribution is typically skewed to the right and the herd average values can be markedly influenced by a small number of extreme values, particularly in smaller herds. Most importantly, CCI and CI do not account for cows that fail to conceive or recalve and therefore might underestimate differences in fertility and the detrimental effects of risk factors. One advantage of CCI and CI is that they are easy to 
7070
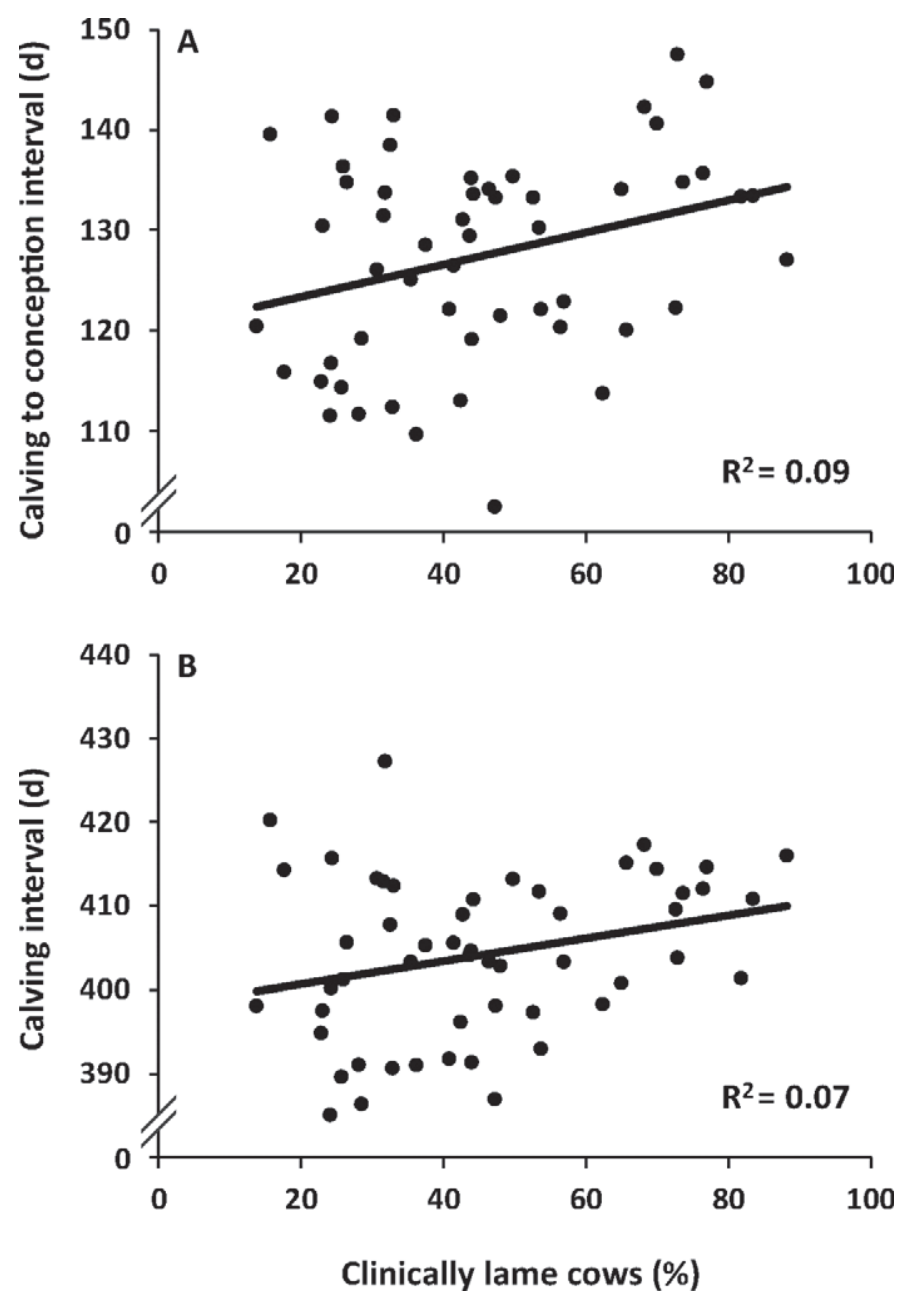

Figure 1. Relationship between calving to conception interval (A) and calving interval (B) and the prevalence of clinical lameness for multiparous cows in 53 dairy herds in the northeastern United States.

calculate from herd records, whereas specialized software is needed to calculate PR as defined here.

The average CCI found in this study (128 d) was lower than the range of 143 to $168 \mathrm{~d}$ reported in previous studies in the United States (Washburn et al., 2002; Norman et al., 2009; DeVries et al., 2010) and similar to averages of 125 and $130 \mathrm{~d}$ reported for Holsteins in Sweden (Löf et al., 2007) and the Netherlands (Windig et al., 2005), respectively. The average CI (404 d) was similar to that reported by Hare et al. (2006) for Holstein cows in the United States and by Windig et al. (2005) and Löf et al. (2007) in Europe, but lower than the averages reported in other US studies (429 d, DeVries and Risco, 2005; 420 d, Caraviello et al., 2006; 419 d, Norman et al., 2009). Differences across studies may be due to the interaction of genetic and management factors. For instance, previous studies (Miller et al., 2007; Norman et al., 2009) reported shorter CCI and $\mathrm{CI}$ in herds that used timed AI.

The CR1 in this study (36\%) was similar to that reported by Norman et al. (2009) for the northeastern United States. Ferguson and Skidmore (2013) reported a higher CR1 of $44 \%$ for a sample of herds selected for excellence in reproductive performance in the United States, whereas Morton (2010) reported a CR of $47 \%$ for the first and second 3-wk periods following the initiation of a breeding program in year-round calving herds in Australia. The IR reported in this study $(60 \%)$ was lower than that reported by Ferguson and Skidmore (2013) for first (86\%) and subsequent AI (63\%) for herds that combined timed AI and natural heat detection and were reported to have much higher insemination intensity than the average in the United States. In contrast, Morton (2010) reported IR of 51 and $57 \%$ for the first and second 3 -wk periods, respectively, after initiation of a breeding program in yearround calving herds in Australia. The PR of $20 \%$ in the current study was higher than the $12 \%$ reported by DeVries and Risco (2005), but lower than the $32 \%$ reported by Ferguson and Skidmore (2013), and similar to the $25 \%$ reported for the northeastern United States by Norman et al. (2009). The variability in the CR, IR, and PR across studies suggests that multiple management factors affect reproductive performance. Pregnancy rate is affected by CR and IR. However, PR can be more easily improved by increasing IR (LeBlanc, 2005). Ferguson and Skidmore (2013) showed that the superior PR of the selected herds in their study was driven by outstanding IR. Insemination rate can be increased by increasing heat detection or by adopting a well-managed, synchronized breeding program (Pursley et al., 1997; Fricke et al., 2003).

We found positive associations between the prevalence of lameness and CCI and CI. Previous research at the cow level found that lame cows had longer CCI (Sprecher et al., 1997; Hernandez et al., 2005; Bicalho et al., 2007). Moreover, Sogstad et al. (2006) reported that cows with ulcers (a painful lesion that commonly alters gait; Chapinal et al., 2009) had longer CI. However, the associations we reported between lameness and CCI and CI were not strong, and we did not find any relationship between lameness and $\mathrm{CR} 1$ or $\mathrm{PR}$ at the herd level. It is possible that these herd-level associations were confounded by environmental factors for which we were not able to control. We also urge caution when extrapolating findings from the cow level to the herd level, as the relationships may not be analogous (Bello et al., 2012). The prevalence of hock and knee injuries was not associated with any reproductive measure. It is unclear whether leg injuries alter behaviors 
such as estrus expression or feeding that could in turn compromise fertility. Further research at the cow and herd level is encouraged.

In conclusion, considerable variation exists in reproductive outcomes among herds in the northeastern United States. Herds with higher lameness prevalence had longer average CCI and CI. However, the magnitude of these effects on herd reproductive performance was small and less than might be expected based on reported cow-level associations. Multiple factors affect herd reproductive performance, but the results from this study indicate that reducing lameness should be part of the overall management plan used to improve reproductive performance at the herd level.

\section{ACKNOWLEDGMENTS}

We extend special thanks to Alejandra Barrientos from the University of British Columbia (UBC) Animal Welfare Program (Vancouver, BC, Canada) and Lindsey Collings from Novus International Inc. (St. Charles, MO) for their work during the data collection phase of this project. We are also grateful to Mercedes Vázquez-Añón, Ed Galo, and Stephanie Gable from Novus International Inc. for their support. We are grateful to the participating dairies and their herd nutritionists for participating in the study. This study was funded by Novus International Inc. General funding for UBC's Animal Welfare Program is through NSERC's Industrial Research Chair program, with industry contributions from the Dairy Farmers of Canada (Ottawa, ON, Canada), Westgen Endowment Fund (Milner, BC, Canada), Zoetis (Kirkland, QC, Canada), BC Cattle Industry Development Fund (Kamloops, BC, Canada), the BC Milk Producers (Burnaby, BC, Canada), and Alberta Milk (Edmonton, AB, Canada).

\section{REFERENCES}

Barrientos, A. K., N. Chapinal, D. M. Weary, E. Galo, and M. A. G. von Keyserlingk. 2013. Hock injuries in freestall housed dairy cows in northeastern US and California. J. Dairy Sci. 96:3758-3765.

Bello, N. M., J. S. Stevenson, and R. J. Tempelman. 2012. Milk production and reproductive performance: Modern interdisciplinary insights into an enduring axiom. J. Dairy Sci. 95:5461-5475.

Bicalho, R. C., F. Vokey, H. N. Erb, and C. L. Guard. 2007. Visual locomotion scoring in the first seventy days in milk: Impact on pregnancy and survival. J. Dairy Sci. 90:4586-4591.

Byrt, T., J. Bishop, and J. B. Carlin. 1993. Bias, prevalence and kappa. J. Clin. Epidemiol. 46:423-429.

Canadian Council on Animal Care (CCAC). 2009. CCAC guidelines on: The care and use of farm animals in research, teaching and testing. CCAC, Ottawa, ON, Canada.

Caraviello, D. Z., K. A. Weigel, P. M. Fricke, M. C. Wiltbank, M. J. Florent, N. B. Cook, K. V. Nordlund, N. R. Zwald, and C. L. Rawson. 2006. Survey of management practices on reproductive performance of dairy cattle on large US commercial farms. J. Dairy Sci. 89:4723-4735.
Chapinal, N., A. Barrientos, M. A. G. von Keyserlingk, E. Galo, and D. M. Weary. 2013. Herd-level risk factors for lameness in freestall farms in northeastern United States and California. J. Dairy Sci. 96:318-328.

Chapinal, N., A. M. de Passillé, D. M. Weary, M. A. G. von Keyserlingk, and J. Rushen. 2009. Using gait score, walking speed, and lying behavior to detect hoof lesions in dairy cows. J. Dairy Sci. 92:4365-4374.

Chapinal, N., C. Goldhawk, A. M. de Passillé, M. A. G. von Keyserlingk, D. M. Weary, and J. Rushen. 2010. Overnight access to pasture does not reduce milk production or feed intake in dairy cattle. Livest. Sci. 129:104-110.

Chebel, R. C., J. E. P. Santos, J. P. Reynolds, R. L. A. Cerri, S. O. Juchem, and M. Overton. 2004. Factors affecting conception rate after artificial insemination and pregnancy loss in lactating dairy cows. Anim. Reprod. Sci. 84:239-255.

DeJarnette, J. M., C. G. Sattler, C. E. Marshall, and R. L. Nebel. 2007. Voluntary waiting period management practices in dairy herds participating in a progeny test program. J. Dairy Sci. 90:1073-1079.

DeVries, A., J. D. Olson, and P. J. Pinedo. 2010. Reproductive risk factors for culling and productive life in large dairy herds in the eastern United States between 2001 and 2006. J. Dairy Sci. 93:613-623.

DeVries, A., and C. A. Risco. 2005. Trends and seasonality of reproductive performance in Florida and Georgia dairy herds from 1976 to 2002. J. Dairy Sci. 88:3155-3165.

Dippel, S., M. Dolezal, C. Brenninkmeyer, J. Brinkmann, S. March, U. Knierim, and C. Winckler. 2009. Risk factors for lameness in freestall housed dairy cows across two breeds, farming systems, and countries. J. Dairy Sci. 92:5476-5486.

Espejo, L. A., M. I. Endres, and J. A. Salfer. 2006. Prevalence of lameness in high-producing Holstein cows housed in freestall barns in Minnesota. J. Dairy Sci. 89:3052-3058.

Ferguson, J. D., and A. Skidmore. 2013. Reproductive performance in a select sample of dairy herds. J. Dairy Sci. 96:1269-1289.

Flower, F. C., and D. M. Weary. 2006. Effect of hoof pathologies on subjective assessments of dairy cow gait. J. Dairy Sci. 89:139-146.

Fricke, P. M., D. Z. Caraviello, K. A. Weigel, and M. L. Welle. 2003. Fertility of dairy cows after resynchronization of ovulation at three intervals following first timed insemination. J. Dairy Sci. 86:3941-3950.

Garbarino, E. J., J. A. Hernandez, J. K. Shearer, C. A. Risco, and W. W. Thatcher. 2004. Effect of lameness on ovarian activity in postpartum Holstein cows. J. Dairy Sci. 87:4123-4131.

González, L. A., B. J. Tolkamp, M. P. Coffey, A. Ferret, and I. Kyriazakis. 2008. Changes in feeding behavior as possible indicators for the automatic monitoring of health disorders in dairy cows. J. Dairy Sci. 91:1017-1028.

Hare, E., H. D. Norman, and J. R. Wright. 2006. Trends in calving ages and calving intervals for dairy cattle breeds in the United States. J. Dairy Sci. 89:365-370.

Hernandez, J. A., E. J. Garbarino, J. K. Shearer, C. A. Risco, and W. T. Thatcher. 2005. Comparison of calving-to-conception interval in dairy cows with different degrees of lameness during the prebreeding postpartum period. J. Am. Vet. Med. Assoc. 227:1284-1291.

Kielland, C., L. E. Ruud, A. J. Zanella, and O. Østerås. 2009. Prevalence and risk factors for skin lesions on legs of dairy cattle housed in freestalls in Norway. J. Dairy Sci. 92:5487-5496.

Landis, R. J., and G. G. Koch. 1977. The measurement of observer agreement for categorical data. Biometrics 33:159-174.

LeBlanc, S. J. 2005. Overall reproductive performance of Canadian dairy cows: Challenges we are facing. Adv. Dairy Technol. $17: 137-148$.

Löf, E., H. Gustafsson, and U. Emanuelson. 2007. Associations between herd characteristics and reproductive efficiency in dairy herds. J. Dairy Sci. 90:4897-4907.

Lombard, J. E., C. B. Tucker, M. A. G. von Keyserlingk, C. A. Kopral, and D. M. Weary. 2010. Associations between cow hygiene, hock injuries, and free stall usage on US dairy farms. J. Dairy Sci. 93:4668-4676. 
Melendez, P., J. Bartolome, L. F. Archbald, and A. Donovan. 2003. The association between lameness, ovarian cysts and fertility in lactating dairy cows. Theriogenology 59:927-937.

Miller, R. H., H. D. Norman, M. T. Kuhn, J. S. Clay, and J. L. Hutchison. 2007. Voluntary waiting period and adoption of synchronized breeding in Dairy Herd Improvement herds. J. Dairy Sci. 90:1594-1606.

Morton, J. M. 2010. Interrelationships between herd-level reproductive performance measures based on intervals from initiation of the breeding program in year-round and seasonal calving dairy herds. J. Dairy Sci. 93:901-910.

Norman, H. D., J. R. Wright, S. M. Hubbard, R. H. Miller, and J. L. Hutchinson. 2009. Reproductive status of Holstein and Jersey cows in the United States. J. Dairy Sci. 92:3517-3528.

Offer, J. E., D. McNulty, and D. N. Logue. 2000. Observations of lameness, hoof conformation and development of lesions in dairy cattle over four lactations. Vet. Rec. 147:105-109.

Olynk, N. J., and C. A. Wolf. 2008. Economic analysis of reproductive management strategies on US commercial dairy farms. J. Dairy Sci. 91:4082-4091.

Pursley, J. R., M. R. Kosorok, and M. C. Wiltbank. 1997. Reproductive management of lactating dairy cows using synchronization of ovulation. J. Dairy Sci. 80:301-306.

Rutherford, K. M. D., F. M. Langford, M. C. Jack, L. Sherwood, A. B. Lawrence, and M. J. Haskell. 2008. Hock injury prevalence and associated risk factors on organic and nonorganic dairy farms in the United Kingdom. J. Dairy Sci. 91:2265-2274.

Santos, J. E. P., H. M. Rutigliano, and M. F. Sa Filho. 2009. Risk factors for resumption of postpartum estrous cycles and embryonic survival in lactating dairy cows. Anim. Reprod. Sci. 110:207-221.

Sogstad, A. M., O. Østeras, and T. Fjeldaas. 2006. Lameness and claw lesions related to reproductive performance and production diseases. J. Dairy Sci. 89:2519-2528.
Sprecher, D. J., D. E. Hostetler, and J. B. Kaneene. 1997. A lameness scoring system that uses posture and gait to predict dairy cattle reproductive performance. Theriogenology 47:1179-1187.

Tenhagen, B. A., C. Vogel, M. Drillich, G. Thiele, and W. Heuwieser. 2003. Influence of stage of lactation and milk production on conception rates after timed artificial insemination following Ovsynch. Theriogenology 60:1527-1537.

Thomsen, P. T., and N. P. Baadsgaard. 2006. Intra- and inter-observer agreement of a protocol for clinical examination of dairy cows. Prev. Vet. Med. 75:133-139.

VanRaden, P. M., A. H. Sanders, M. E. Tooker, R. H. Miller, H. D. Norman, M. T. Kuhn, and G. R. Wiggans. 2004. Development of a national genetic evaluation for cow fertility. J. Dairy Sci. $87: 2285-2292$

von Keyserlingk, M. A. G., A. K. Barrientos, K. Ito, E. Galo, and D M. Weary. 2012. Benchmarking cow comfort on North American freestall dairies: Lameness, leg injuries, lying time, facility design, and management for high-producing Holstein dairy cows. J. Dairy Sci. 95:7399-7408

Walker, S. L., R. F. Smith, D. N. Jones, J. E. Routly, M. J. Morris, and H. Dobson. 2010. The effect of a chronic stressor, lameness, on detailed sexual behaviour and hormonal profiles in milk and plasma of dairy cattle. Reprod. Domest. Anim. 45:109-117.

Washburn, S. P., W. J. Silvia, C. H. Brown, B. T. McDaniel, and A. J. McAllister. 2002. Trends in reproductive performance in southeastern Holstein and Jersey DHI herds. J. Dairy Sci. 85:244-251.

Windig, J. J., M. P. L. Calus, and R. F. Veerkamp. 2005. Influence of herd environment on health and fertility and their relationship with milk production. J. Dairy Sci. 88:335-347. 